Original Article

Pankaj Raj Nepal

FCPS Neurosurgery

B\&C Medical College Teaching Hospital,

Address for correspondence:

Pankaj Raj Nepal, FCPS Neurosurgery

Deputy Director and Head of Department, Department of Neurosurgery

B\&C Medical College Teaching Hospital, Birtamode, Jhapa.

Phone No: +977-9801098106

Email: drprnepal@yahoo.com

Date submitted : 01 August 2019

Date accepted : 31 August 2019
Nepal Journal of Neurosciences 16:32-37, 2019

\section{Early Experience of Microsurgical Clipping of Ruptured Intracranial Aneurysms.}

To see the outcome in patients following microsurgical clipping of ruptured intracranial aneurysms and analyze the results.It is a prospective analytical study were demographic data of the patient, initial World Federation of Neurosurgical Societies (WFNS) grade, Fischer's grade, duration of ictus, intraoperative rupture, incidence of clinical vasospasm and Modified Rankin Scale (MRS) at three months were collected and analysis was done using SPSS-20.

There were total 19 cases of microsurgical clipping, with mean age 55.4yrs, where 52.4\% were females. Average duration of Ictus was 24.5 hours. Most common WFNS grade on presentation was grade II (42\%) and Fischer's CT grade was IV (58\%). Commonest site of aneurysm was ACom (53\%) and were 15.8\% intraoperatie rupture. Ventriculo-peritoneal (VP) shunt and severe clinical vasospasm both were seen in $10.5 \%$. Overall mortality was $11 \%$ and MRS 1 and 2 were obtained in 10\% and $58 \%$ respectively. Good initial WFNS, internal carotid aneurysm, absence of hydrocephalus and absence of clinical vasospasm were significantly associated with better MRS at three months. Factors associated with better outcome were good initial WFNS, internal carotid aneurysm, absence of hydrocephalus and absence of clinical vasospasm.

Key words: Aneurysms, Modified Rankin Scale, Microsurgical clipping, vasospasm, hydrocephalus.

Mortality of aneurysm following microsurgical clipping is as high as $26 \%$ in various series. ${ }^{1,5,6,14}$ Mortality in the aneurysm surgery is mainly due to vasospasm, which is approximately $13.5 \% .5,6,10,11$ Hydrocephalus following subarachnoid hemorrhage who needs ventriculoperitoneal shunt is around $10 \%$ in different series. ${ }^{3,16}$ 
Microsurgical Clipping of Intracranial Aneurysm

With the objective toevaluate the outcome in patients following microsurgical clipping of ruptured intracranial aneurysms and analyze their results this study was performed.

\section{Methods and Materials:}

Study design: Prospective analytical study. Sampling technique: Non- probability consecutive sampling. Sample size: 19 cases. Site of study: B and C Medical College and Teaching hospital, Birtamode, Jhapa, Nepal.Duration of Study:One Year (13th Feb, 2018 to 12 Feb, 2019)

Data collection and analysis:

All the cases of the ruptured intracerebral aneurysms who underwent microsurgical clipping by the authorwas collected prospectively. Demographic data of the patients, age, gender, initial World Federation of Neurosurgical Societies (WFNS) grade (Table 1), Fishers grade (Table 2), duration of ictus, location of aneurysm, intraoperative rupture,hydrocephalus(HCP)needingVentriculoperitoneal (VP) shunt, clinical vasospasm and Modified Rankin Scale (MRS) (Table 3) at three months were collected in a preformed proforma.

\begin{tabular}{|l|l|}
\hline Grade & Findings \\
\hline I & GCS 15, no motor deficit \\
\hline II & GCS 13-14, no motor deficit \\
\hline III & GCS 13-14, motor deficit \\
\hline IV & GCS 7-12 +/- motor deficit \\
\hline V & GCS 3-6, motor deficit present or absent \\
\hline \multicolumn{2}{|c|}{ Table 1: WFNS Grading for Subarachnoid } \\
Hemorrhage
\end{tabular}

\begin{tabular}{|l|l|}
\hline Grade & CT Findings \\
\hline $\mathbf{1}$ & No hemorrhage evident \\
\hline $\mathbf{2}$ & $\begin{array}{l}\text { Diffuse or vertical layer subarachnoid } \\
\text { hemorrhage }<1 \text { mm thick }\end{array}$ \\
\hline $\mathbf{3}$ & $\begin{array}{l}\text { Localized clot and/ or vertical layer of suba- } \\
\text { rachnoid hemorrhage }>\text { / = 1mm thick }\end{array}$ \\
\hline $\mathbf{4}$ & $\begin{array}{l}\text { Intracerebral or intraventricular clot, with or } \\
\text { without a diffuse subarachnoid hemorrhage }\end{array}$ \\
\hline
\end{tabular}

Table 2: Fisher's scale of SAH

\begin{tabular}{|l|l|}
\hline Score & Description \\
\hline $\mathbf{0}$ & No symptoms at all \\
\hline $\mathbf{1}$ & $\begin{array}{l}\text { No significant disability despite symptoms; } \\
\text { able to carry out all usual duties and } \\
\text { activities }\end{array}$ \\
\hline $\mathbf{2}$ & $\begin{array}{l}\text { Slight disability; unable to carry out all } \\
\text { previous activities, but able to look after own } \\
\text { affairs without assistance }\end{array}$ \\
\hline $\mathbf{3}$ & $\begin{array}{l}\text { Moderate disability; requiring some help, but } \\
\text { able to walk without assistance }\end{array}$ \\
\hline $\mathbf{4}$ & $\begin{array}{l}\text { Moderately severe disability; unable to walk } \\
\text { without assistance and unable to attend to } \\
\text { own bodily needs without assistance }\end{array}$ \\
\hline $\mathbf{5}$ & $\begin{array}{l}\text { Severe disability; bedridden, incontinent and } \\
\text { requiring constant nursing care and attention }\end{array}$ \\
\hline $\mathbf{6}$ & Dead \\
\hline
\end{tabular}

Table 3: Modified Rankin Scale(MRS)

Continuous variables like age and duration of ictuswere shown as mean and standard deviation (SD). Categorical data like gender, initial WFNS grade, Fisher's grade, location of aneurysms, HCP who needed VP shunt, clinical vasospasm, and MRS at three months were presented as percentage. Fisher's Exact test was used to see the association between different categorical data and MRS at three months. In the same way, One Way ANOVA test was used to analyze the association between duration of ictus and MRS at three months.

\section{Results:}

There were total of 19 cases that underwent microsurgical clipping during the study duration. The mean age of presentation was 55.4 (SD 13.06) years, where there were $52.4 \%$ females and $47.4 \%$ males. Average duration of Ictus of aneurysm rupture was 24.5 (SD 14.24) hours. Most common WFNS on presentation was grade II (42\%) (Figure 1) and Fischer CT grade was IV (58\%) (Figure2). Commonest aneurysm by location was ACom (53\%) (Figure 3), among them anterior and inferior pointing were $40 \%$ each followed by $20 \%$ being superior pointing. There was $15.8 \%$ intraoperatie rupture of aneurysm during aneurysm dissection. Around 10.5\% of patient developed hydrocephalus during the follow up of three months who required VP shunt and $10.5 \%$ patient developed severe clinical vasospasm. Overall mortality was $11 \%$ with moderate severe disability $11 \%$. MRS 1 was obtained in 10\% and MRS 2 in 58\% (Figure 4). 


\section{Nepal et al}

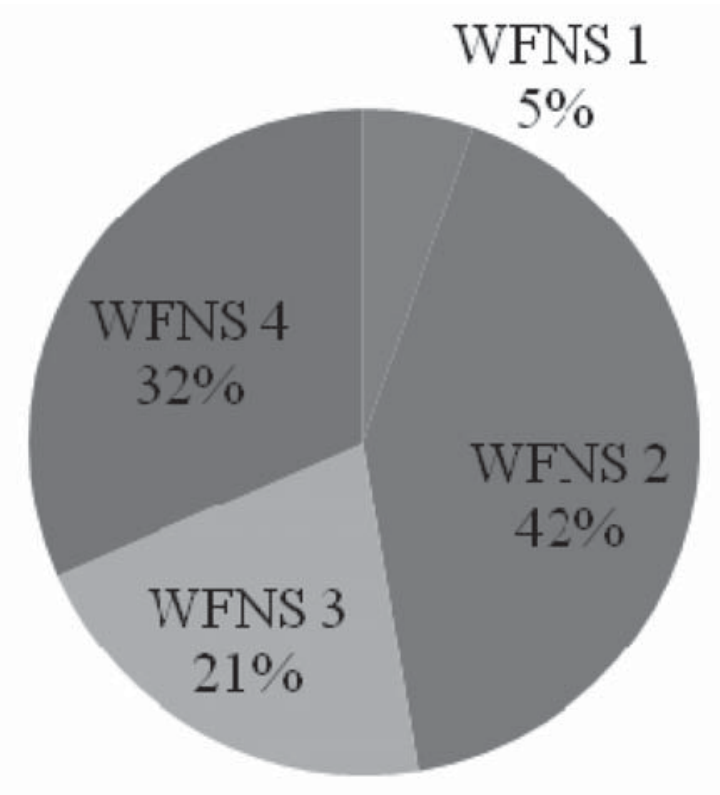

Figure 1: WFNS grading on presentation

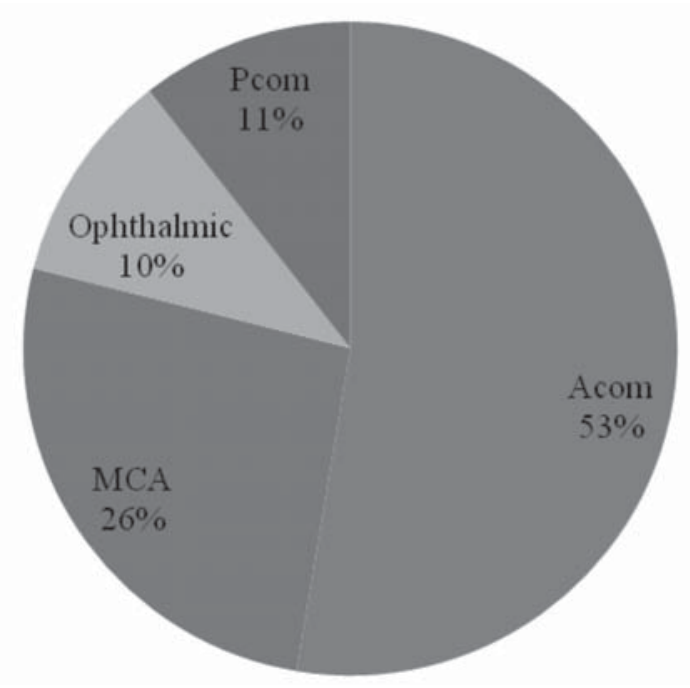

Figure 3: Location of Aneurysms

Age and gender didn't have significant association with MRS at three months. WFNS grading of subarachnoid hemorrhage(SAH) seems to have significant association with MRS, where higher the grade poorer was the outcome and vice versa. Fisher's grade of SAH at the time of presentation didn't had significant association with outcome of patients in terms of MRS. However, location of aneurysm was significantly associated with MRS at three months; the presence of Pcom aneurysms was significantly

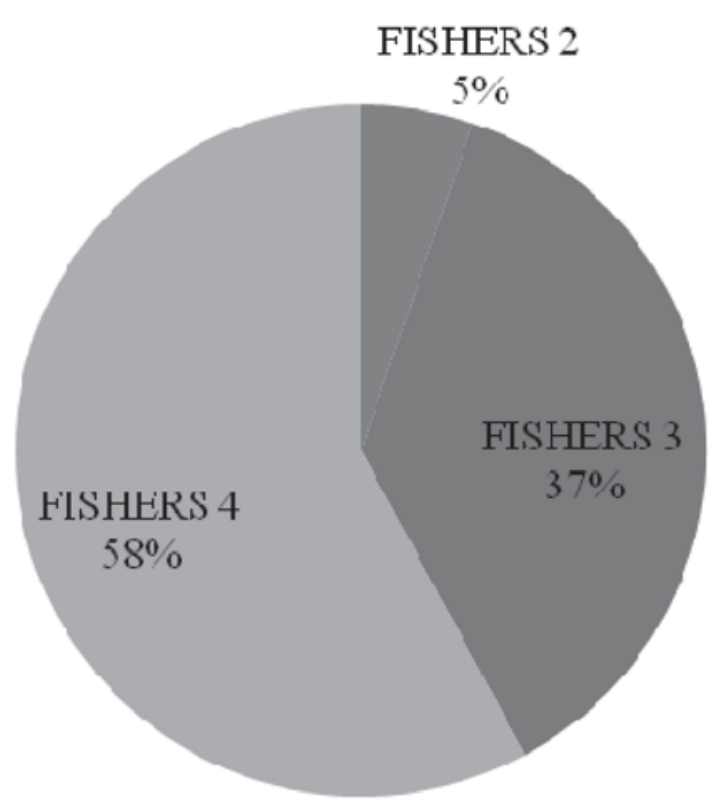

Figure 2: Fisher's grade on presentation

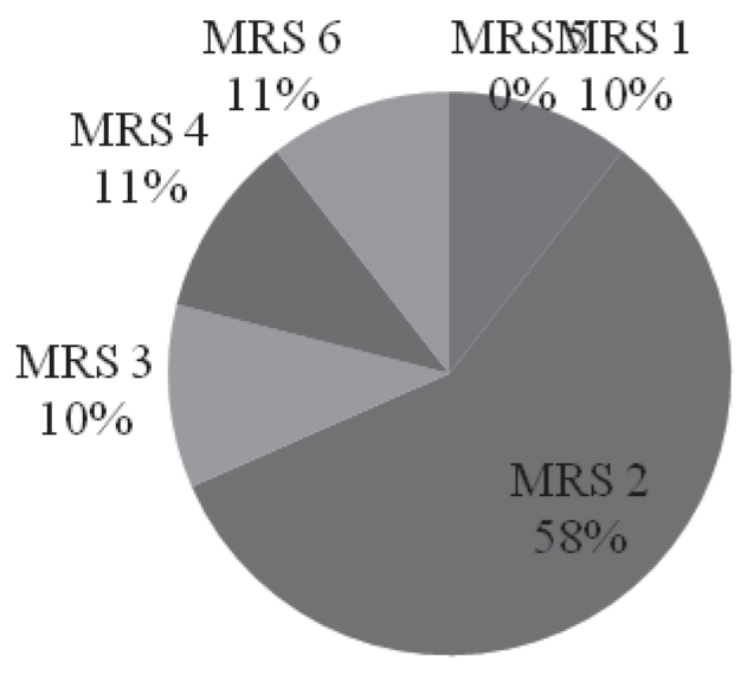

Figure 4: MRS at three months

associated with favorable outcome. Similarly, presence of hydrocephalus requiring VP shunt and clinical vasospasm had significant association with MRS. Hydrocephalus requiring VP shunt didn't increased mortality; rather, had significant association with unfavorable outcome. However, presence of clinical vasospasm was significantly associated with mortality within three months (Table 4).Duration of ictus was not significantly associated with the MRS at three months (Table 5). 


\begin{tabular}{|c|c|c|c|c|c|c|c|}
\hline & & \multicolumn{6}{|c|}{ MRS at 3months } \\
\hline & & 1 & 2 & 3 & 4 & 6 & P Value \\
\hline \multirow{6}{*}{ Age } & $30-39$ & 0 & 2 & 0 & 0 & 0 & \multirow{6}{*}{.763} \\
\hline & $40-49$ & 0 & 3 & 1 & 0 & 1 & \\
\hline & $50-59$ & 0 & 3 & 0 & 1 & 1 & \\
\hline & $60-69$ & 1 & 2 & 0 & 0 & 0 & \\
\hline & $70-79$ & 1 & 1 & 0 & 1 & 0 & \\
\hline & 80-89 & 0 & 0 & 1 & 0 & 0 & \\
\hline \multirow{2}{*}{ Gender } & Female & 1 & 6 & 0 & 1 & 2 & \multirow{2}{*}{.646} \\
\hline & Male & 1 & 5 & 2 & 1 & 0 & \\
\hline \multirow{4}{*}{$\begin{array}{l}\text { Initial WFNS grading of } \\
\text { SAH }\end{array}$} & 1 & 1 & 0 & 0 & 0 & 0 & \multirow{4}{*}{$.012 *$} \\
\hline & 2 & 1 & 7 & 0 & 0 & 0 & \\
\hline & 3 & 0 & 3 & 1 & 0 & 0 & \\
\hline & 4 & 0 & 1 & 1 & 2 & 2 & \\
\hline \multirow{3}{*}{ Fisher's grade of SAH } & 2 & 1 & 0 & 0 & 0 & 0 & \multirow{3}{*}{.096} \\
\hline & 3 & 1 & 6 & 0 & 0 & 0 & \\
\hline & 4 & 0 & 5 & 2 & 2 & 2 & \\
\hline \multirow{4}{*}{ Location of Aneurysms } & Acom & 0 & 7 & 0 & 2 & 1 & \multirow{4}{*}{$.045^{*}$} \\
\hline & MCA & 0 & 2 & 2 & 0 & 1 & \\
\hline & Ophthalmic & 2 & 0 & 0 & 0 & 0 & \\
\hline & PCOM & 0 & 2 & 0 & 0 & 0 & \\
\hline \multirow{2}{*}{ VP shunt following HCP } & no & 2 & 11 & 2 & 0 & 2 & \multirow{2}{*}{$.023^{*}$} \\
\hline & yes & 0 & 0 & 0 & 2 & 0 & \\
\hline \multirow{2}{*}{ Clinical Vasospasm } & no & 2 & 11 & 2 & 2 & 0 & \multirow{2}{*}{$.023^{*}$} \\
\hline & yes & 0 & 0 & 0 & 0 & 2 & \\
\hline
\end{tabular}

Table 4: Analysis of different categories with the MRS at three months.

\begin{tabular}{|c|c|c|c|c|c|c|}
\hline & \multirow{2}{*}{$\mathrm{N}$} & \multirow{2}{*}{ Mean } & \multirow{2}{*}{ SD } & \multicolumn{2}{|c|}{ 95\% CI for Mean } & \multirow{2}{*}{$\mathrm{P}$ value } \\
\hline & & & & Lower & Upper & \\
\hline 1 & 2 & 18.50 & 4.950 & -25.97 & 62.97 & \\
\hline 2 & 11 & 31.00 & 12.602 & 22.53 & 39.47 & \\
\hline 3 & 2 & 8.00 & 5.657 & -42.82 & 58.82 & .076 \\
\hline 4 & 2 & 27.50 & 20.506 & -156.74 & 211.74 & \\
\hline 6 & 2 & 9.00 & 2.828 & -16.41 & 34.41 & \\
\hline
\end{tabular}

Table 5: One way ANOVA test between duration of ictus and MRS at 3 months. 


\section{Discussion:}

Various studies had shown poor outcome with advancing age; however, this study with mean age of 55.4 years showed no significant association of age with the outcome at three months., ${ }^{5,6}$ In previous literatures, they had shown no significant association of gender with the outcome of patients, and this was similar in our study as well, despite of slight female predominance. ${ }^{5,6,18,19}$ The large international cooperative study had shown good condition at the time of admission is associated with better outcome with overall mortality of around 26\%, similarly, in this study, better WFNS grading at the time of admission was significantly associated with better MRS at three months, compared to those who had poor WFNS grade at admission with overall mortality of $11 \%$. $^{5,6,15}$

Minimal clot distribution in CT scan had been associated with favorable outcome in the previous literature; however, in this study the association was not significant and might be due to small sample size of Fisher's grade 1 and 2 at presentation. 5,6,7,12,13

In this study, all the cases were of anterior circulating aneurysms; though, some literatures groupedPcom aneurysm in posterior circulation. ${ }^{4}$ The presence of ophthalmic and Pcom aneurysmswere significantly associated with favorable outcome at three months and this might be largely due to less cerebral dissection during surgery.Similar results were obtained in previous studies where better outcome was seen with MCA aneurysm and internal carotid aneurysm, when they were compared with vertebrobasilar or other anterior circulating aneurysms. ${ }^{5,6,7}$

Presence of clinical vasospasm was significantly associated with higher mortality in our study. There was $10.5 \%$ vasospasm developed during post operative course was similar to other studies. ${ }^{10,11,14}$ Presence of hydrocephalus was also associated with poor outcome in our studies, and was similar with many other studies from the past. ${ }^{3,14}$

\section{Conclusion:}

As a young neurosurgeon in an early career working at far eastern part of Nepal, where facilities are very limited and transporting patients are with great risks, we are able to produce similar outcome in the microsurgical clipping of aneurysm when compared to the results of better centers around the world. In this study factors associated with better outcome were seen with good initial WFNS, internal carotid aneurysm, absence of hydrocephalus and clinical vasospasm.
Acknowledgement: I highly appreciate the microsurgical teaching of Late.Prof. Upendra P. Devkota, without which I don't think I could have produced this result.

\section{References:}

1. Devkota UP, Aryal KR. Result of surgery for ruptured intracranial aneurysms in Nepal. Br J Neurosurg 15(1): 13-6, 2001

2. Fox J. Intracranial Aneurysms. New York: SpringerVerlag;1983.

3. Graff-Radford NR , Torner J , Adams HP Jr , Kassell NF . Factors associated with hydrocephalus after subarachnoid hemorrhage. A report of the Cooperative Aneurysm Study .Arch Neurol46 :744 - 752, 1989

4. International Study of Unruptured Intracranial Aneurysms Investigators. Unruptured intracranial aneurysms-risk of rupture and risks of surgical intervention. N Engl J Med 339(24):1725-1733, 1998

5. KassellNF ,Torner JC , Haley EC Jr , Jane JA, Adams HP , Kongable GL . The International Cooperative Study on the Timing of Aneurysm Surgery. Part 1: overall management results .J Neurosurg73:18 36, 1990

6. KassellNF ,Torner JC, Jane JA , Haley EC Jr , Adams HP . The International Cooperative Study on the Timing of Aneurysm Surgery. Part 2: surgical results. J Neurosurg73:37 - 47, 1990

7. KassellNF , Torner JC . The International Cooperative Study on Timing of Aneurysm Surgery - an update .Stroke15:566 - 570, 1984

8. Molyneux A , Kerr R. International Subarachnoid Aneurysm Trial (ISAT) Collaborative Group , Stratton I, Sandercock P, Clarke M , Shrimpton J , Holman R . International Subarachnoid Aneurysm Trial (ISAT) of neurosurgical clipping versus endovascular coiling in 2143 patients with ruptured intracranial aneurysms: a randomized trial .J Stroke Cerebrovasc Dis 11:304 - 314, 2002

9. Molyneux A , Kerr R ; International Subarachnoid Aneurysm Trial (ISAT) Collaborative Group , Stratton I, Sandercock P , Clarke M , Shrimpton J , Holman R . International Subarachnoid Aneurysm Trial (ISAT) of neurosurgical clipping versus endovascular coiling in 2143 patients with ruptured intracranial aneurysms: a randomized trial .J Stroke Cerebrovasc Dis11:304 - 314, 2002

10. Pearl JD, Macdonald RL. Vasospasm after aneurysmal subarachnoid hemorrhage: need for further study. ActaNeurochirSuppl 105:207-210, 2008 
11. Pluta RM, Hansen-Schwartz J, Dreier J, et al. Cerebral vasospasm following subarachnoid hemorrhage: time for a new world of thought. Neurol Res 31(2):151158, 2009

12. Provenzale JM, Hacein-Bey L. CT evaluation of subarachnoid hemorrhage: a practical review for the radiologist interpreting emergency room studies. EmergRadiol 16(6):441-451, 2009

13. Rajbhandari B, Sharma MR, Shilpakar SK, Sedhain G, Pradhanang A, Shrestha RK, Kafle P, Shrestha DK, Koirala PR. Prediction of aneurysm location based on pattern of bleed on CT scan. Journal of Society of Surgeons of Nepal 21(1): 21-28, 2018

14. Roka YB, Shrestha M, Puri PR, Adhikari HB. Surgery for Intracerebral Aneurysms in Eastern Nepal: A New Beginning. Nepal Journal of Neuroscience 9:5-9, 2012

15. Sharma GR, Kausal P, Jha R, Khadka N, Adhikari DR, Bista P, Sultania PK. Outcome of Microsurgical Clipping of Intracranial Aneurysms in Bir Hospital. Nepal Journal of Neuroscience 8(2): 137-142, 2011

\section{Microsurgical Clipping of Intracranial Aneurysm}

16. Sheehan JP, Polin RS, Sheehan JM, et al. Factors associated with hydrocephalus after aneurysmal subarachnoid hemorrhage. Neurosurgery 45(5):1120-1127:discussion 1127-1128, 1999

17. Shrestha P, Singh AM, Dhungana I. Cerebral Aneurysm Surgery in B \& B hospital: An Experience of Last One Year. BBMed 1: 23-28, 2017

18. Weir B. Unruptured intracranial aneurysms: a review. J Neurosurg 96(1):3-42, 2002

19. Wiebers DO, Whisnant JP, Huston 3rd J, et al. Unruptured intracranial aneurysms: natural history, clinical outcome, and risks of surgical and endovascular treatment. Lancet 362(9378):103-110, 2003

20. WolstenholmeJ ,Rivero-Arias O, Gray A, Molyneux AJ , Kerr RS , Yarnold JA, Sneade M ; International Subarachnoid Aneurysm Trial (ISAT) Collaborative Group . Treatment pathways, resource use, and costs of endovascular coiling versus surgical clipping after a SAH .Stroke39:111 - 119, 2008

21. Woo D, Khoury J, Haverbusch MM, et al. Smoking and family history and risk of aneurysmal subarachnoid hemorrhage. Neurology 72(1):69-72, 2009 